\title{
Making the Legal and Ethical Case for Universal Screening for Postpartum Mood and Anxiety Disorders in Pediatric Primary Care
}

Amy Lewis Gilbert, JD, MPH ${ }^{1,2}$; Casey Balio, BA 3 ; Nerissa S. Bauer, MD, MPH ${ }^{1,2}$

${ }^{1}$ Indiana University School of Medicine, Department of Pediatrics, Children's Health Services Research, Indianapolis, IN, USA

${ }^{2}$ Regenstrief Institute, Inc., Indianapolis, IN, USA

${ }^{3}$ Indiana University, Richard M. Fairbanks School of Public Health, Indianapolis, IN

Corresponding Author: Amy Lewis Gilbert, JD, MPH; Children's Health Services Research, 410 West 10 ${ }^{\text {th }}$ Street, HS 2000, Indianapolis, IN 46202; amylewis@iu.edu; 317.278.7490 (Phone); 317.278.0456 (Fax)

This is the author's manuscript of the article published in final edited form as:

Gilbert, A. L., Balio, C., \& Bauer, N. S. (2017). Making the Legal and Ethical Case for Universal Screening for Postpartum Mood and Anxiety Disorders in Pediatric Primary Care. Current Problems in Pediatric and Adolescent Health Care, 47(10), 267-277. https://doi.org/10.1016/j.cppeds.2017.08.001 


\title{
Making the Legal and Ethical Case for Universal Screening for Postpartum Mood and Anxiety Disorders in Pediatric Primary Care
}

\author{
Amy Lewis Gilbert, JD, MPH \\ Casey Balio, BA \\ Nerissa S. Bauer, MD, MPH
}

\begin{abstract}
Postpartum Depression (PPD), part of a larger spectrum of Perinatal Mood and Anxiety Disorders, affects up to $15 \%$ of women following the birth of an infant. Fathers may also be affected. PPD not only affects caregivers, but also impacts infants through mechanisms such as inadequate caregiver-infant interactions and non-adherence to safety practices. The negative impact on infants may extend across the life course through adulthood. This article seeks to move the needle toward universal screening for PPD using validated tools in pediatric primary care settings for new caregivers by making the legal and ethical case for this course of action in a manner that is both compelling and accessible for clinicians. Toward this end, we summarize current literature as it applies to provider responsibilities, liabilities and perspectives; and caregiver autonomy, confidentiality and privacy. We then assess utility by balancing the benefits and burdens of this approach to practices, providers and caregivers; and take the analysis one step further by extending looking across multiple populations to assess distributive justice. We conclude that there is a strong ethical case for universal screening for PPD in pediatric primary care settings using validated tools when informed consent can be obtained and appropriate follow-up services are available and accessible. Clinical considerations, practical resources and areas ripe for future research are also addressed.
\end{abstract}




\section{BACKGROUND}

\section{Overview of Postpartum Mood and Anxiety Disorders and Their Impact}

Postpartum depression (PPD) affects up to $15 \%$ of women following the birth of an infant. PPD is a part of a larger spectrum of postpartum mood and anxiety disorders, or PMADs. ${ }^{1,2}$ Postpartum anxiety is a separate condition that affects up to $18 \%$ of all mothers, making it equally worrisome, that can occur separately or combined with $\mathrm{PPD}^{3}$. The risk of PPD is more common within the first four months postpartum, but can occur anytime during the first year. Having a prior or family history of depression, being a teen mother or experiencing stressful situations, such as living in poverty or limited social support, are known risk factors of PPD. In a prospective cohort study, thoughts of death and dying or difficulty falling asleep at one month postpartum were associated with PPD at four months ${ }^{4}$. Fathers can also develop symptoms of PPD, but these often go undiagnosed., ${ }^{5,6}$ PD not only affects caregivers, but also frequently results in inadequate caregiver-infant interactions and non-adherence to safety practices. ${ }^{7}$ The negative impact on infants may extend into early childhood, ${ }^{8-10}$ resulting in a higher risk of developmental delays and behavioral issues. Exposure to parental mood disorders is one of ten known Adverse Childhood Experiences, or ACEs ${ }^{11}$, that have been shown to be associated with poor health, social and behavioral outcomes spanning the life course. It is therefore important to screen and identify at-risk individuals early, so caregivers experiencing PMADs can receive appropriate treatment and support in a timely manner.

\section{Overview of Current Screening Practices and Tools}

In the past, screening for PPD and other PMADs fell largely to adult medicine primary care providers including family practitioners, obstetricians and internists. In recent years, 
however, there has been increasing recognition that pediatric primary care providers have a unique opportunity to identify PMADs. Most of the research informing this recognition has been focused on mothers and PPD. It is recommended that at least 8 well-child visits occur during the first year of a child's life, resulting in earlier and more frequent interactions with new mothers. ${ }^{12}$ Research also shows that women report a host of issues accessing healthcare for themselves, such that screening for PPD in pediatric settings may be the only way to catch them in the busy first year of their children's lives. ${ }^{13}$ Although not all women are able to attend every recommended well-child visit, mothers may be more likely to seek care for their children than they would for themselves, and be more honest in their responses when screening is put in the context of benefiting their child's health. ${ }^{14}$

While many healthcare providers report feeling confident in their ability to identify PPD informally through conversations and general impressions, ${ }^{15-17}$ surveillance of this nature has been found to be significantly less effective than screening with a validated tool. ${ }^{17-19}$ Support for, and adoption of, screening for PPD by pediatric primary care providers using validated tools during well-child visits in the first year of life is increasing. A number of studies have demonstrated the feasibility and success of this approach ${ }^{12,20-22}$ and several professional organizations and government agencies including the United States Preventive Services Task Force (USPSTF), ${ }^{23}$ American Academy of Pediatrics (AAP) ${ }^{12}$ and Centers for Medicare and Medicaid Services (CMS) ${ }^{24}$ support this movement (See Table 1: Support for Screening in Pediatric Settings with Validated Tools).

The most commonly used tools for identifying symptoms of PPD are the Edinburgh Postnatal Depression Scale (EPDS) and the Patient Health Questionnaire (PHQ-2 or PHQ9). These instruments have been widely accepted, translated into more than twenty languages, 
and validated for a variety of patient populations including the EPDS for adolescent mothers ${ }^{25}$ and fathers ${ }^{26,27}$. Either tool can reliably be used in the context of screening for PPD among postpartum mothers, as scores using the PHQ or EPDS have been shown to be concordant. ${ }^{28}$ However, the EPDS specifically includes 3 items to capture anxiety symptoms (feeling scared/panicky, anxious or worried, and blamed self unnecessarily); whereas the PHQ is specific to depressive symptoms only ${ }^{29}$. Thus, the choice of which screen to use may ultimately be based upon provider preference. Depending on the particular population being screened, sensitivity for the EPDS ranges from 0.63 to 1.00 with specificity typically between $0.78-0.87 .{ }^{30,31}$ Similarly, the PHQ-2 sensitivity ranges from 0.75 to 1.00 with specificities between 0.62 to $0.88^{32}$ and for the PHQ-9 sensitivity is 0.75 and specificity of $0.91 .^{32}$ The EPDS has been used and studied more extensively than the PHQ-2 or PHQ-9 among postpartum women, ${ }^{30}$ but all of these tools show promising results. Average screening times have been shown to be less than 3 minutes $^{21,22,33}$ with most conversations lasting less than 3 minutes ${ }^{22}$ and providers requiring less than one minute to score and interpret the results. ${ }^{21}$ It is important to note that all of these tools are to be used for screening, and not diagnostic, purposes. ${ }^{22}$

Table 1: Support for Screening in Pediatric Settings with Validated Tools

\begin{tabular}{|l|l|l|}
\hline \multicolumn{1}{|c|}{ Organization } & \multicolumn{1}{|c|}{ Recommendations/Support } & \multicolumn{1}{c|}{ Tool Endorsed } \\
\hline American Academy & Maternal depression screening at 1, 2, 4, and & EPDS \\
of Pediatrics / Bright & 6 month visits & PHQ-2 \\
Futures & & PHQ-9 \\
Guidelines & & \\
\hline US Preventive & Grade B recommendation: Pregnant and & Provides evidence review \\
\hline
\end{tabular}




\begin{tabular}{|c|c|c|}
\hline $\begin{array}{l}\text { Services Task Force } \\
\text { Recommendation } \\
\text { Statement }^{23,30}\end{array}$ & $\begin{array}{l}\text { postpartum women should be screened and } \\
\text { supported with treatment and follow-up } \\
\text { when necessary (support for this population } \\
\text { to be screened in either obstetric or pediatric } \\
\text { settings) }\end{array}$ & for both EPDS and PHQ \\
\hline $\begin{array}{l}\text { Centers for } \\
\text { Medicare \& } \\
\text { Medicaid Services } \\
(\mathrm{CMS})^{24}\end{array}$ & $\begin{array}{l}\text { Some State Medicaid agencies cover PPD } \\
\text { screening at well-child visits through either } \\
\text { the mother's or child's Medicaid ID (via the } \\
\text { Early and Periodic Screening, Diagnostic } \\
\text { and Treatment component of Medicaid). } \\
\text { Examples include: } \\
\text { - Colorado } \\
\text { - Illinois }{ }^{36} \\
\text { - Minnesota }{ }^{37} \\
\text { - North Dakota } \\
\text { - Virginia }\end{array}$ & $\begin{array}{l}\text { Vary by state, but include } \\
\text { EPDS, Beck Depression } \\
\text { Inventory-II (BDI-II), } \\
\text { Center for } \\
\text { Epidemiological Studies } \\
\text { Depression Scale (CES- } \\
\text { D), PHQ-9, Parenting } \\
\text { Stress Index (PSI) }\end{array}$ \\
\hline $\begin{array}{l}\text { National } \\
\text { Association of } \\
\text { Pediatric Nurse } \\
\text { Practitioners } \\
\text { (PNPs) }\end{array}$ & $\begin{array}{l}\text { States that PNPs are “skillful in screening } \\
\text { mothers for risk of maternal depression” and } \\
\text { supports early interventions to promote } \\
\text { psychological well-being for parents }\end{array}$ & N/A \\
\hline $\begin{array}{l}\text { Mental Health } \\
\text { America }^{41}\end{array}$ & $\begin{array}{l}\text { Supports screening for PMADS in a variety } \\
\text { of settings including pediatrics. Also states }\end{array}$ & N/A \\
\hline
\end{tabular}




\begin{tabular}{|l|l|l|}
\hline that the cost of screening and follow-up care \\
should be covered in all health plans and \\
encourages the co-location of mental health \\
professionals in settings where screenings \\
occur
\end{tabular} \mid

A previous analysis conducted by Chaudron et al. in 2007 looked at the basic question of whether or not screening for postpartum depression at pediatric primary care visits was legally and ethically justified, and determined that it was. ${ }^{42}$ Why, then, in light of this analysis and the recommendations of so many professional organizations are we still talking about screening for PPD and other PMADs in pediatric settings rather than consistently practicing and teaching this approach? Unfortunately, recent reviews demonstrate that there is still considerable room for improvement. Although the proportion of pediatricians who report usually inquiring about or screening mothers for PPD has increased significantly in the past decade from $33 \%$ to $44 \%$, the fact that this number remains so low is concerning. ${ }^{43}$ Moreover, once PPD is suspected, less than half of those with positive screens receive referrals to mental health services ${ }^{21}$ - an ethically problematic and avoidable state of affairs that leaves both infant and caregiver in harms way.

\section{Making the Legal and Ethical Case for Universal Screening in Pediatric Primary Care}

This article seeks to move the needle forward even further by making the legal and ethical case for universal screening for PMADs using validated tools in pediatric primary care settings for new caregivers of infants in a manner that is both compelling and accessible for clinicians. Our approach will be to summarize the current literature and apply a series of 
guidelines deemed important to determining whether a proposed clinical or public health initiative is ethical. These guidelines call for: (1) maximizing benefits while minimizing burdens; (2) assessing the likelihood of effectiveness, voluntariness of the intervention, and distributive justice; (3) respecting patient and parent autonomy, privacy, and confidentiality; (4) considering the responsibility and liability of the provider; and (5) seeking input from all stakeholders. ${ }^{44,45}$ We will then state our conclusions, make specific recommendations for establishing a universal standard of care, and identify areas in need of further research.

\section{LEGAL AND ETHICAL CONSIDERATIONS}

As we think through the legal and ethical case for screening mothers for PMADs in pediatric primary health care settings, precedent can be helpful. For this reason, we will not only draw from literature that pertains to health care surveillance and screening for PPD, the most studied of all PMADs, but also highlight literature that focuses on screening parenting adults for other health or psychosocial risk factors that have the potential to impact the health of the child. It is important to note up front that screening in these cases places a burden on the caregiver alone for a benefit that ultimately accrues to both the caregiver and child. In circumstances such as this, it is ethically imperative that positive screens be followed up with support for both the caregiver and child ${ }^{12,44}$ Italicized terms throughout this section have been defined below in Table 2: Relevant Legal and Ethical Terms.

Table 2: Relevant Legal and Ethical Terms

\begin{tabular}{|c|l|}
\hline \multicolumn{1}{|c|}{ Term } & \multicolumn{1}{c|}{ Definition } \\
\hline Fiduciary Duty & Providers have an elevated legal duty to exercise the highest standard of \\
\hline
\end{tabular}




\begin{tabular}{|c|c|}
\hline & $\begin{array}{l}\text { loyalty and care to patients by virtue of their control over important subject } \\
\text { matter, the vulnerability of patients, and the resulting potential for abuse }{ }^{46} \text {. }\end{array}$ \\
\hline Beneficence & $\begin{array}{l}\text { A provider's obligation to act in a manner that benefits a patient, especially } \\
\text { with regard to the patient's health. The three obligations of beneficence } \\
\text { include preventing evil or harm, removing evil or harm, and promoting } \\
\text { good. }{ }^{47}\end{array}$ \\
\hline Non-Maleficence & $\begin{array}{l}\text { Often considered a fourth obligation of beneficence, non-maleficence } \\
\text { mandates that a provider ought not inflict evil or harm. }{ }^{47}\end{array}$ \\
\hline Autonomy & 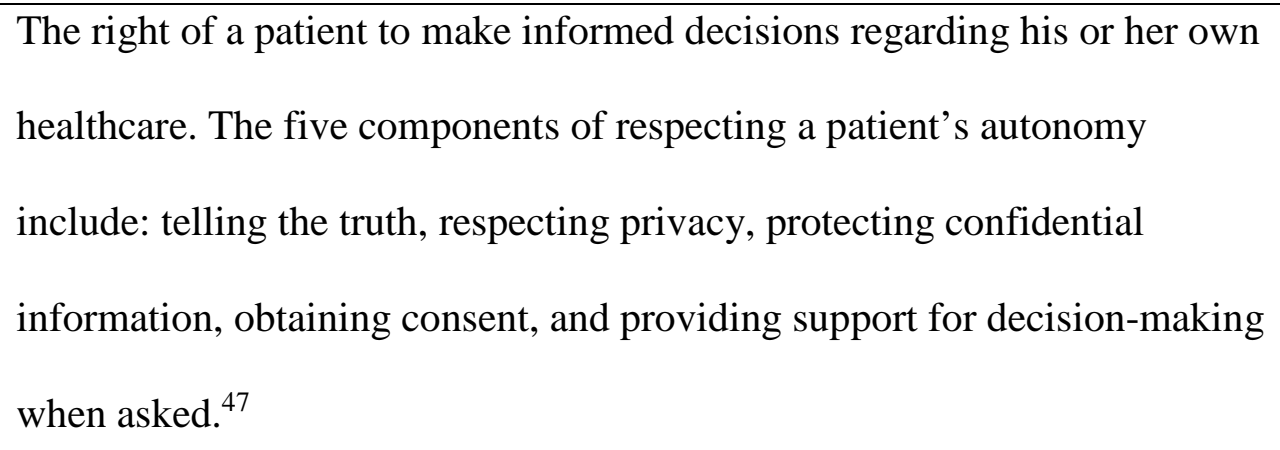 \\
\hline Informed Consent & $\begin{array}{l}\text { Requires that a patient be informed of the harms and benefits of the } \\
\text { proposed course of action, that the patient have the capacity to understand } \\
\text { the information and make a decision, and that the patient have a clear } \\
\text { understanding that the proposed course of action may be accepted or } \\
\text { declined. }{ }^{47}\end{array}$ \\
\hline Confidentiality & $\begin{array}{l}\text { The duty of a provider to maintain secrecy regarding a patient’s health } \\
\text { information absent patient consent to disclose or a legally mandated duty to } \\
\text { breach }^{46} \text {. }\end{array}$ \\
\hline Privacy & $\begin{array}{l}\text { The right of patients to make decisions about how their personal } \\
\text { information is shared }{ }^{48} \text {. }\end{array}$ \\
\hline
\end{tabular}




\begin{tabular}{|l|l|}
\hline Utility & The principle of maximizing benefit while minimizing burden or harms. ${ }^{49}$ \\
\hline Distributive Justice & $\begin{array}{l}\text { A specific component of justice where social benefits and burdens should } \\
\text { be equally realized throughout the community or population, regardless of } \\
\text { disease status or demographic factors. }{ }^{47}\end{array}$ \\
\hline
\end{tabular}

\section{Responsibilities, Liabilities and Perspectives of the Pediatric Primary Care Provider}

The inherently unequal distribution of power in the relationship between healthcare providers and patients gives rise to providers having a fiduciary duty to their patients. In the simplest of terms, this means that providers have a legally heightened responsibility to provide the best and most honest care possible to their patients ${ }^{47}$ due to their elevated knowledge and the relative vulnerability of their patients. ${ }^{46}$ In pediatrics, this means that providers have a duty to make the child's interests paramount by providing direct care, making appropriate referrals, and generally doing what is in the best interest of the child. Because children are minors, and therefore lack the capacity to understand and consent to their own healthcare in most instances, we as a society have deemed parents or legal guardians responsible for making healthcare decisions on their behalf. For this reason, a pediatric provider's fiduciary duty extends beyond the child to include a responsibility to disclose relevant information to the parent or legal guardian about factors that may ultimately impact the child's health, so that the best care possible may be provided to the child.

The bioethical principles of beneficence and non-maleficence further elucidate a provider's responsibility to do no harm, prevent evil or harm, remove evil or harm, and promote good. ${ }^{47}$ If a provider screens for, and identifies, symptoms of a PMAD, he or she has an ethical 
responsibility to refer or otherwise connect that caregiver to appropriate services and care so as to avoid harm, and promote wellbeing, of both the infant and the caregiver. ${ }^{12}$ It is important to note that providers are increasingly being asked to screen caregivers in pediatric primary care for a number of environmental and psychosocial risks to children including poverty, family support systems, and parental substance use. ${ }^{12}$ These risk factors, along with PMADs, are part of a larger group of increasingly recognized ACEs, which have been shown to have a dose-response association with negative health outcomes throughout the life course. ${ }^{11}$ This movement toward screening for social determinants of health in clinical settings has the potential to significantly improve child health, but providers have not necessarily been quick to adopt it for a variety of reasons. ${ }^{50}$ In a recent survey of pediatricians, 57\% considered PPD screening within the scope of their practice, but only $45 \%$ felt confident in their ability to identify PPD or provide appropriate support to mothers. ${ }^{15}$ Pediatricians attributed reservations about screening to a lack of training, low confidence in their ability to correctly use screening tools and interpret results, and limited knowledge about the adult mental health resources available in their communities. ${ }^{15,16}$ Medical liability, or a provider's legal responsibility for an adverse patient outcome, is another topic that clinicians frequently express concern about in the context of screening caregivers for PMADs in pediatric settings. Medical liability or malpractice laws vary significantly by state, ${ }^{51}$ but in very general terms liability hinges on whether or not a given provider exercised reasonable care and skill in a manner consistent with an established standard of care. ${ }^{46}$ In a legal setting, complexity is likely to arise if the caregiver, as opposed to the patient, is the one to suffer damage - and if a clear standard of care has not yet been established. These complexities highlight the importance (described in more detail below) of obtaining informed consent from caregivers prior to screening, and developing an established standard of care for 
screening in pediatric settings that spans both individual practice locations and the field at large. In summary, an argument can be made that pediatric primary care providers have an ethical responsibility to screen for PMADs and consider screening to be within their scope of care. This responsibility, however, appears to be at odds with their sense of discomfort around screening, management and risk of liability. This discordance may best be resolved with education, which will be discussed in more detail below.

\section{Caregiver Autonomy, Confidentiality, and Privacy}

Very rarely can we justify infringing on one person’s rights to help another, particularly if little benefit accrues to the infringed person, but screening for PMADs clearly has the potential to not only benefit the child, but also the caregiver. Autonomy is a term used to describe both a patient's right to make his or her own healthcare decisions, and a provider's responsibility to acknowledge and protect that right (see Table II: Relevant Legal and Ethical Terms). In the context of screening a caregiver for risk factors that may impact a child's health, the caregiver's autonomy must also be respected. Although obtaining informed consent from a caregiver prior to screening for risk factors that may impact the health of a child is not standard practice, respect for autonomy supports the position that caregivers should be presented with information about the screening process, informed of any known potential benefits and harms (to both the caregiver and the child), and then offered a choice to participate in screening (or not). Without consent, screening has the potential to become coercive and paternalistic, and the practice may in fact undermine a caregiver's trust in his or her child's provider and sabotage open communication. A few practical considerations related to obtaining consent from caregivers in pediatric settings include state-specific legal requirements regarding capacity to consent, whether the consent is 
written or verbal, what the benefits and risks of screening and documentation of screening actually are in the particular setting, and how and where the receipt of consent will be documented (e.g., the child’s medical record).

Confidentiality refers to the professional responsibility of providers, who have access to both medical records and patient communications, to hold patient information in confidence. ${ }^{46,52}$ When discussing the personal health information of patients - including risk exposures such as PMADs - with parents or legal guardians, information provided by these caregivers is likewise to be held in confidence. One notable limit to confidentiality that may arise in the context of screening for PMADs includes mandatory reporting to law enforcement in the case of suspected child maltreatment or, in some states, exposure of a child to caregiver-reported or suspected intimate partner violence. This legal requirement to breach confidentiality in certain circumstances is one that providers should share with caregivers in the process of obtaining informed consent.

In contrast to confidentiality, privacy (as it is understood in the context of federal privacy regulations such as the Health Information Portability and Accountability Act) refers to the right of patients to make decisions about how their personal information, including personal health information, is shared. ${ }^{48}$ Parents and legal guardians have the right to make decisions about how information is disclosed on behalf of their children, including the sharing of medical record information such as documentation of risk exposures like PMADs. It is important to remember that all legal guardians of a given pediatric patient have access to, and can direct the sharing of, personal information contained in that patient's medical record. For this reason, it is important to be mindful of the impact that documenting a positive PMAD screen for one guardian may have when there is reason to believe the other guardian might try to access and use that information in 
a damaging way. Again, this privacy caveat is one that should be shared with caregivers in the process of obtaining informed consent. Given the limits of both confidentiality and privacy, it is important for practices to carefully consider what should be documented in the patient's medical record in light of the particular populations served and the relevant laws of the state. Whereas some practices may choose only to document that a screening tool was administered, others may also elect to include details about scoring, referrals and follow-up.

\section{Utility - Balancing the Benefits and Burdens}

Utility is defined as maximizing the benefits of a particular intervention while minimizing its burden. When considering the implementation of a new clinical initiative, utility should be evaluated and modifications made as necessary to improve the benefit to burden ratio. The following paragraphs briefly summarize the known benefits and burdens of screening for PMADs in pediatric primary care settings using validated tools, and then consider the utility of implementing this practice on a widespread scale.

Benefits. Utilization of validated brief screening instruments allows providers to detect worrisome signs and symptoms early when PMADs are present or emerging so they may be treated more easily. The use of screening tools to jump start conversations may also serve to establish therapeutic alliances between providers and caregivers, helping caregivers understand that providers may be trusted sources of parenting support. Routine preventive care visits present providers with an ideal opportunity to discuss concerns related to an infant's growth and development, as well as provide critical parenting support for new caregivers. As there are

approximately eight recommended visits in an infant's first year, ${ }^{34,53}$ pediatric providers are wellpositioned to monitor caregiver mood, observe caregiver-infant interactions and administer 
screening. ${ }^{12,21,22,42,53,54}$ Once a caregiver screens positive for PMAD symptoms, knowledgeable providers can ensure timely referrals for additional diagnostic evaluation and evidence-based supportive services. For providers working within a co-located family practice model or within an integrated behavioral health care practice, pediatric providers can collaborate directly with mental health providers to provide coordinated services within the medical home. Provision of universal screening and timely services for support and treatment benefit not only the caregiver, but also the child.

Burdens. The costs of screening may be economic or otherwise, and may accrue to the healthcare provider, practice, or caregiver. To the practice and provider, direct costs include monetary outputs associated with screening (e.g., printing for paper-based screening, algorithm development and hardware costs for electronic screening, and data management) and indirect costs such as provider training, provider time and any other resources necessary to redesign the clinical flow. ${ }^{16,18}$ While these costs are important and sometimes cited as barriers to screening, the actual time required for screening and scoring is minimal, as previously described, and many of the tools themselves are free to use and available in the public domain. For example, the PHQ tools can be accessed at www.phqscreeners.com, and the EPDS is available online in a number of locations. Regarding billing, as of January 2017, CPT Code 96161 may be used to report the administration of a caregiver-focused health risk assessment with scoring and documentation, using a standardized instrument, for the benefit of the patient (e.g., the EPDS). ${ }^{55}$

In terms of burdens that accrue to the caregiver, the primary cost may be a potential loss of confidentiality or privacy as discussed above. Additional concerns include the low positive predictive value of screening tools (e.g., estimated around $40 \%$ for the EPDS). ${ }^{33}$ False positives can potentially impact the mother by exposing her to unnecessary concern and stigma associated 
with being labeled as depressed. ${ }^{56,57}$ False positives may also negatively impact providers and the practice by commanding unnecessary investments of time and resources. A majority of studies, however, report minimal to no adverse effects of screening on caregivers, and several report on no harms at all. 23,30,58

An important consideration in assessing burden is that caregivers themselves report being more likely to open up about their own health to their children's primary care providers when they have an established relationship, ${ }^{59}$ which speaks to there being a lesser burden for some caregivers than others. The existence of a trusting relationship is particularly relevant in the context of caregivers' concerns about being judged or reported to child protective services. ${ }^{59}$ Of note, however, one study found that all participating mothers connected their own emotional health to their child's wellbeing, and most believed they had a responsibility to maintain their own emotional health for the benefit their child. ${ }^{59}$ This, along with other studies about mothers' approval of their children's providers screening for PPD, ${ }^{13}$ and a general receptiveness to being screened using the EPDS, ${ }^{60}$ show that there is substantial maternal support for implementing screening in this setting. ${ }^{13,61,62}$ Support for screening among fathers and other caregivers has not yet been evaluated to the same extent, highlighting a need for further research in this area.

Utility. We first consider utility - the balancing of benefits and burdens - in settings where follow-up supports are available versus settings in which they are not. In the case of a positive screen in a setting where appropriate services are not accessible for any reason, the potential harms (e.g., emotional distress) become considerable and the benefits negligible, making screening in this context unjustifiable. ${ }^{44}$ When appropriate services are available, however, the potential for benefit clearly outweighs the risk of harm. Another way of thinking this through is in the context of insurance. If a positive screen occurs and the caregiver is referred 
for services, but that caregiver is either uninsured or underinsured, then he or she may practically be unable to access services. ${ }^{12}$ For this reason, efforts should be made by practices to ensure access to follow-up care for all caregivers who screen positive, regardless of insurance coverage. Toward this end, some state AAP chapters have taken it upon themselves to take steps toward ensuring access within their local jurisdictions. ${ }^{12}$

We next consider utility in situations where screening using a validated tool is universal versus situations in which it is not. When screening for PMADs is not universal, either at the discretion of the provider or through selective screening of high-risk populations, the utility is reduced. As demonstrated in the literature, informal provider surveillance is often ineffective, resulting in a large number of false negatives. ${ }^{17,18,63}$ Similarly, if providers only screen a predetermined sub-population with known risk factors, the providers risk missing symptoms among caregivers of other populations and giving those caregivers a false sense of security about their risk of PMADs. This issue of distributive justice, and its implications, is discussed in more detail below. In contrast, if screening is administered universally to all caregivers of infants in a particular practice, providers are most likely to detect PMAD symptoms while not exposing any one population to differential harm thus maximizing utility across populations in a just manner.

To summarize, from an ethical standpoint, the utility of screening for PMADs is maximized when informed consent is obtained and universal screening is conducted using a validated screening tool in practices where appropriate follow-up services can be provided or referred. In such situations, the harms have been shown to be minimal or nonexistent and the benefits to mother and child are significant. ${ }^{18}$

\section{Justice - Balancing the Benefits and Burdens Across Different Populations}


The concept of justice in medical ethics refers to the distribution of health resources in a fair and equitable manner. ${ }^{47}$ Distributive justice takes this one step further by requiring a balancing of benefits and burdens across a variety of populations, such that no one population shoulders significant burden without the potential for significant benefit. ${ }^{47}$ In light of known disparities of prevalence and severity of PPD across different caregiver populations, such as young, low-income, and single mothers, ${ }^{12,21}$ justice is an important consideration. Teen mothers, in particular, are at elevated risk with prevalence documented as high as $56 \%{ }^{64}$ While the temptation might be to screen only those populations at increased risk in a given practice setting because a topical analysis suggests utility may be maximized in this way, doing so would ignore a large proportion of caregivers who may likewise be affected. As one public health ethicist explained, perhaps the most significant harm that can occur happens when an intervention fails to include a certain group of people such that individuals within that group mistakenly believe they are not at risk. ${ }^{45}$ If caregivers feel that they are not at risk for PPD because they have not been screened, particularly if they know that others have been screened and/or they have limited knowledge about risk factors for PPD, the intervention has done those caregivers harm. ${ }^{20}$ It is for this reason that adhering to professional guidelines, such as the USPSTF recommendation that all women be screened for PPD regardless of risk factors when support services are available, is so important. ${ }^{23,45}$ Striving for distributive justice in the context of screening for PMADs in pediatric primary care settings also requires that less-studied populations of caregivers, such as fathers and adoptive parents, also be screened - although additional research should be conducted to determine whether the benefits and burdens of the intervention differ significantly for these populations. 


\section{A Special Note About Fathers}

Estimates suggest that as many as $10 \%$ of new fathers show symptoms of PPD, but there is high variability among these estimates. ${ }^{65,66}$ Most studies suggest that symptoms for mothers occur most frequently between 3-6 months after birth, ${ }^{65}$ and that paternal PPD is highly correlated with maternal PPD ${ }^{65,67}$. Paternal PPD has been shown to have many of the same effects on infants as maternal $\mathrm{PPD}^{68}$ - for example, children of fathers who experienced paternal PPD are more likely to experience psychiatric diagnoses at 7 years ${ }^{69}$ - but studies suggest that the effects of maternal PPD are more likely to be long-lasting. ${ }^{69,70}$ In dual-parent households, fathers often shield children from the effects of maternal PPD, ${ }^{71-74}$ but if fathers are also experiencing PPD they not only fail to assume this protective role, but the overall effects on the child's health and well-being are also exacerbated. ${ }^{71}$ While mothers attend preventive care visits more often than fathers, fathers should also be screened for PMADs when they do attend. Ethical considerations for fathers mirror those of mothers, although utility analyses may differ slightly given that the risk of long-term effects are lower with paternal PPD unless both parents are experiencing symptoms, in which case the harms are magnified. Informed consent and universal screening practices should apply with equal force to fathers.

\section{CONCLUSIONS, CLINICAL IMPLICATIONS, AND FUTURE DIRECTIONS}

Given the ever-growing evidence base regarding the negative effects of adverse childhood experiences on early brain and child development and implications for poorer health over the life course $\mathrm{e}^{8-11}$, professional organizations increasingly recommend that pediatric providers implement universal screening for PPD and other PMADs at key preventive care visits. ${ }^{12,23,30,34,40,41}$ While only a limited number of state Medicaid agencies currently provide 
reimbursement for screening in this setting, ${ }^{35-39}$ it is important nonetheless for practices and providers to understand that offering universal screening for PMADs in pediatric primary care will ultimately lead to improved health outcomes for patients.

There are several legal parameters to be mindful of in redesigning the clinical flow to implement this process including the limits of confidentiality and privacy, and the hypothetical potential for medical liability if a provider fails to exercise reasonable care and skill in a manner consistent with the evolving standard of care. Specific documentation requirements, in particular, are something that should be carefully considered so as to avoid breaches that may adversely impact caregiver safety and wellbeing. These are parameters that will ideally be assessed in the clinical redesign process by the practice or system, as opposed to the individual provider, in collaboration with someone who understands relevant jurisdictional law and system policies (e.g., general counsel or a risk management professional). Other tangible resources for guidance and support include working with chapters of professional organizations to advocate for billing and reimbursement issues at the state level, or for technical assistance in screening efforts by seeking help from the AAP Screening Technical Assistance and Resource Center. Clinicians can also connect with local chapters of national and international non-for-profit organizations such as Postpartum Support International (www.postpartum.net) to learn about state-specific resources available in local communities.

Another consideration that is beyond the scope of this article is the role of clinical training and professional education in helping to further establish the standard of care by providing information about how best to develop a trusting relationship with new caregivers such that they feel comfortable with screening, the evidence base for universal screening, the use of 
validated tools, the necessity of appropriate follow-up, and (in clinical environments) any system-specific policies and procedures.

Lastly, there exist several gaps in the literature related to this topic that invite future research, including prevalence rates of PMADs other than PPD for various populations; perspectives on screening of fathers and other non-maternal caregivers; the cost effectiveness of integrating screening into pediatric practice; and comparative analyses of different reimbursement practices to guide future policy.

In conclusion, although there is much research yet to be done, a strong legal and ethical case already exists for implementing universal screening for PMADs in pediatric primary care settings using validated tools when informed consent can be obtained and appropriate follow-up services are available and accessible. 


\section{REFERENCES}

1. Jolley SN, Betrus P. Comparing postpartum depression and major depressive disorder: issues in assessment. Issues Ment Health Nurs. 2007;28(7):765-780. doi:10.1080/01612840701413590.

2. Grant KA, McMahon C, Austin MP. Maternal anxiety during the transition to parenthood: a prospective study. J Affect Disord. 2008;108:101-111. doi:10.1016/j.jad.2007.10.002.

3. Farr SL, Dietz PM, O’Hara MW, Burley K, Ko JY. Postpartum Anxiety and Comorbid Depression in a Population-Based Sample of Women. $J$ Womens Health (Larchmt). 2013;0(0):120-128. doi:10.1089/jwh.2013.4438.

4. Chaudron LH, Klein MH, Remington P, Palta M, Allen C, Essex MJ. Predictors, prodromes and incidence of postpartum depression. J Psychosom Obstet Gynaecol. 2001;22(2):103-112. doi:10.3109/01674820109049960.

5. Matthey S, Barnett B, Howie P, Kavanagh DJ. Diagnosing postpartum depression in mothers and fathers: Whatever happened to anxiety? J Affect Disord. 2003;74(2):139-147. doi:10.1016/S0165-0327(02)00012-5.

6. Paulson J, Dauber S, Leiferman J. Individual and combined effects of postpartum depression in mothers and fathers on parenting behavior. Pediatrics. 2006;118(2):659-668. doi:10.1542/peds.2005-2948.

7. Field T. Postpartum depression effects on early interactions, parenting, and safety practices: A review. Infant Behav Dev. 2010;33(1):1-6. doi:10.1016/j.infbeh.2009.10.005.

8. Bauer NS, Gilbert AL, Carroll AE, Downs SM. Associations of early exposure to intimate partner violence and parental depression with subsequent mental health outcomes. JAMA Pediatr. 2013;167(4):341-347. doi:10.1001/jamapediatrics.2013.780.

9. Gilbert AL, Bauer NS, Carroll AE, Downs SM. Child exposure to parental violence and psychological distress associated with delayed milestones. Pediatrics. 2013;132(6):e1577e1583.

10. Matijasevich A, Murray J, Cooper PJ, et al. Trajectories of maternal depression and offspring psychopathology at 6 years: 2004 Pelotas cohort study. J Affect Disord. 2015;174:424-431. doi:10.1016/j.jad.2014.12.012.

11. Felitti VJ, Anda RF, Nordenberg D, et al. Relationship of childhood abuse and household dysfunction to many of the leading causes of death in adults: The adverse childhood experiences (ACE) study. Am J Prev Med. 1998;14(4):245-258. doi:10.1016/S07493797(98)00017-8.

12. Earls MF. Incorporating recognition and management of perinatal and postpartum depression into pediatric practice. Pediatrics. 2010;126(5):1032-1039. doi:10.1542/peds.2010-2348.

13. Kahn RS, Wise PH, Finkelstein JA, Bernstein HH, Lowe JA, Homer CJ. The Scope of Unmet Maternal Health Needs in Pediatric Settings. Pediatrics. 1999;103(3).

14. Zuckerman BS, Beardslee WR. Maternal Depression: A Concern for Pediatricians. Pediatrics. 1987;79(1).

15. Olson AL, Kemper KJ, Kelleher KJ, Hammond CS, Zuckerman BS, Dietrich AJ. Primary Care Pediatricians' Roles and Perceived Responsibilities in the Identification and Management of Maternal Depression. Pediatrics. 2002;110(6).

16. Heneghan AM, Morton S, DeLeone NL. Paediatricians' attitudes about discussing maternal depression during a paediatric primary care visit. Child Care Health Dev. 
2007;33(3):333-339. doi:10.1111/j.1365-2214.2006.00648.x.

17. Evins GG, Theofrastous JP, Galvin SL. Postpartum depression: A comparison of screening and routine clinical evaluation. Am J Obstet Gynecol. 2000;182(5):1080-1082. doi:10.1067/mob.2000.105409.

18. Gjerdingen DK, Yawn BP. Postpartum depression screening: importance, methods, barriers, and recommendations for practice. J Am Board Fam Med. 2007;20(3):280-288. doi:10.3122/jabfm.2007.03.060171.

19. Heneghan AM, Silver EJ, Bauman LJ, Stein REK. Do Pediatricians Recognize Mothers With Depressive Symptoms? Pediatrics. 2000;106(6).

20. Feinberg E, Smith M V., Morales MJ, Claussen AH, Smith DC, Perou R. Improving Women's Health during Internatal Periods: Developing an Evidenced-Based Approach to Addressing Maternal Depression in Pediatric Settings. J Women's Heal. 2006;15(6):692703. doi:10.1089/jwh.2006.15.692.

21. Chaudron LH, Szilagyi PG, Kitzman HJ, Wadkins HIM, Conwell Y. Detection of postpartum depressive symptoms by screening at well-child visits. Pediatrics. 2004;113(3 Pt 1):551-558. doi:10.1542/peds.113.3.551.

22. Olson AL, Dietrich AJ, Prazar G, Hurley J. Brief Maternal Depression Screening at WellChild Visits. Pediatrics. 2006;118(1).

23. Siu AL, Bibbins-Domingo K, Grossman DC, et al. Screening for Depression in Adults. JAMA. 2016;315(4):380. doi:10.1001/jama.2015.18392.

24. Wachino, V (Director, Center for Medicaid and CHIP Services ). Maternal Depression Screening and Treatment: A Critical Role for Medicaid in the Care of Mothers and Children.; 2016.

25. Venkatesh KK, Zlotnick C, Triche EW, Ware C, Phipps MG. Accuracy of brief screening tools for identifying postpartum depression among adolescent mothers. Pediatrics. 2014;133(1):e45-53. doi:10.1542/peds.2013-1628.

26. Matthey S, Barnett B, Kavanagh DJ, Howie P. Validation of the Edinburgh Postnatal Depression Scale for men, and comparison of item endorsement with their partners. $J$ Affect Disord. 2001;64(2-3):175-184. http://www.ncbi.nlm.nih.gov/pubmed/11313084. Accessed February 23, 2017.

27. Fisher SD, Kopelman R, O’Hara MW. Partner report of paternal depression using the Edinburgh Postnatal Depression Scale-Partner. Arch Womens Ment Health. 2012;15(4):283-288.

28. Yawn BP, Pace W, Wollan PC, et al. Concordance of Edinburgh Postnatal Depression Scale (EPDS) and Patient Health Questionnaire (PHQ-9) to assess increased risk of depression among postpartum women. J Am Board Fam Med. 2009;22(5):483-491. doi:10.3122/jabfm.2009.05.080155.

29. Mitchell AJ. The 3 item anxiety subscale of the Edinburgh Postpartum Depression Scale may detect postnatal depression as well as the 10 item full scale. Evid Based Ment Health. 2009;12(2):44. doi:10.1136/ebmh.12.2.44.

30. O’Connor E, Rossom RC, Henninger M, Groom HC, Burda BU. Primary Care Screening for and Treatment of Depression in Pregnant and Postpartum Women. JAMA. 2016;315(4):388. doi:10.1001/jama.2015.18948.

31. Cox JL, Holden JM, Sagovsky R. Detection of postnatal depression. Development of the 10-item Edinburgh Postnatal Depression Scale. Br J Psychiatry. 1987;150:782-786. http://www.ncbi.nlm.nih.gov/pubmed/3651732. Accessed February 22, 2017. 
32. Gjerdingen D, Crow S, McGovern P, Miner M, Center B. Postpartum depression screening at well-child visits: validity of a 2-question screen and the PHQ-9. Ann Fam Med. 2009;7(1):63-70. doi:10.1370/afm.933.

33. Mitchell AJ, Coyne JC. Do ultra-short screening instruments accurately detect depression in primary care? A pooled analysis and meta-analysis of 22 studies. Br J Gen Pract. 2007;57(535):144-151. http://www.ncbi.nlm.nih.gov/pubmed/17263931. Accessed February 23, 2017.

34. Hagan J, Shaw J, Duncan P. Bright Futures Guidelines. 4th ed. Elk Grove Village, IL: American Academy of Pediatrics; 2017.

35. Colorado Deparment of Health Care Policy and Financing. Postpartum Depression Screenings and Oayment in the Pediatric Primary Care Office (Provider Bulletin B1400355); 2014. https://www.colorado.gov/pacific/sites/default/files/Bulletin_0814_B1400355.pdf.

36. Illinois Department of Healthcare and Family Services. Handbook for Providers of Healthy Kids Services: Chapter HK-200 Policy and Procedures for Health Care for Children.; 2017. https://www.illinois.gov/hfs/SiteCollectionDocuments/hk200.pdf.

37. Minnesota Department of Human Services. Provider Manual: Child and Teen Checkups. http://www.dhs.state.mn.us/main/idcplg?IdcService=GET_DYNAMIC_CONVERSION\& RevisionSelectionMethod=LatestReleased\&dDocName=dhs16_150092\#maternal. Published 2017.

38. North Dakota Department of Human Services. Medicaid Coding Guideline: Maternal Depression Screening.; 2015.

https://www.nd.gov/dhs/services/medicalserv/medicaid/docs/cpt/maternal-depressionscreen.pdf.

39. Virginia Department of Medical Assistance Services. BabyCare Manual: Covered Services and Limitations.; 2016. http://www.dmas.virginia.gov/Content_pgs/mchhome.aspx.

40. National Association of Pediatric Nurse Practitioners. NAPNAP Position Statement on the PNP's Role in Supporting Infant and Family Well-Being During the First Year of Life. $J$ Pediatr Heal Care. 2011;25(2):9A-11A.

41. Mental Health America. Position Statement 49: Perinatal Mental Health. http://www.mentalhealthamerica.net/issues/position-statement-49-perinatal-mental-health.

42. Chaudron LH, Szilagyi PG, Campbell AT, Mounts KO, McInerny TK. Legal and Ethical Considerations: Risks and Benefits of Postpartum Depression Screening at Well-Child Visits. Pediatrics. 2007;119(1):123-128. doi:10.1542/peds.2006-2122.

43. Kerker BD, Storfer-Isser A, Stein REK, et al. Identifying Maternal Depression in Pediatric Primary Care. J Dev Behav Pediatr. 2016;37(2):113-120. doi:10.1097/DBP.0000000000000255.

44. Childress JF, Faden RR, Gaare RD, et al. Public Health Ethics: Mapping the Terrain. $J$ Law, Med Ethics. 2002;30(2):170-178. doi:10.1111/j.1748-720X.2002.tb00384.x.

45. Kass NE. An ethics framework for public health. Am J Public Health. 2001;91(11):17761782. http://www.ncbi.nlm.nih.gov/pubmed/11684600. Accessed February 22, 2017.

46. Hall MA, Bobinski MA, Orentlicher D. Medical Liability and Treatment Relationsihps. New York, NY: Aspen Publishers; 2008.

47. Beauchamp T, Childress J. Principles of Biomedical Ethics. 5th ed. New York, NY: Oxford University Press; 2001. 
48. Brodnik MS, Rinehart-Thompson LA, Reynolds RB. Fundamentals of Law for Health Informatics and Information Management. Chicago: American Health Information Management Association; 2012.

49. Coughlin SS. Case Studies in Public Health Ethics. 2nd ed. American Public Health Association; 2009.

50. Kogan MD, Schuster MA, Yu SM, et al. Routine assessment of family and community health risks: parent views and what they receive. Pediatrics. 2004;113(6 Suppl):19341943. doi:10.1542/peds.2005-1090.

51. National Conference of State Legislatures. Medical Liability/Medical Malpractice Laws. http://www.ncsl.org/research/financial-services-and-commerce/medical-liability-medicalmalpractice-laws.aspx.

52. McWay DC. Legal and Ethical Aspects of Health Information Management. Third. New York: Cengage Learning; 2010.

53. Liberto TL. Screening for Depression and Help-Seeking in Postpartum Women During Well-Baby Pediatric Visits: An Integrated Review. J Pediatr Heal Care. 2012;26(2):109117. doi:10.1016/j.pedhc.2010.06.012.

54. Olson AL, Kemper KJ, Kelleher KJ, Hammond CS, Zuckerman BS, Dietrich AJ. Primary Care Pediatricians’ Roles and Perceived Responsibilities in the Identification and Management of Maternal Depression. Pediatrics. 2002;110(6).

55. AAP Division of Health Care Finance, Dolan B. CPT code changes for health risk assessments take effect Jan. 1. AAP News. 2016.

56. Mishina H, Takayama JI. Screening for maternal depression in primary care pediatrics. Curr Opin Pediatr. 2009;21(6):789-793. doi:10.1097/MOP.0b013e328331e798.

57. Myers ER, Aubuchon-Endsley N, Bastian LA, et al. Efficacy and Safety of Screening for Postpartum Depression. Agency for Healthcare Research and Quality (US); 2013. http://www.ncbi.nlm.nih.gov/pubmed/23678510. Accessed February 21, 2017.

58. Leung SSL, Leung C, Lam TH, et al. Outcome of a postnatal depression screening programme using the Edinburgh Postnatal Depression Scale: a randomized controlled trial. J Public Health (Bangkok). 2011;33(2):292-301. doi:10.1093/pubmed/fdq075.

59. Heneghan AM, Mercer M, DeLeone NL. Will mothers discuss parenting stress and depressive symptoms with their child's pediatrician? Pediatrics. 2004;113(3 Pt 1):460-467. http://www.ncbi.nlm.nih.gov/pubmed/14993535. Accessed February 20, 2017.

60. Gemmill AW, Leigh B, Ericksen J, Milgrom J. A survey of the clinical acceptability of screening for postnatal depression in depressed and non-depressed women. BMC Public Health. 2006;6:211. doi:10.1186/1471-2458-6-211.

61. Walker LO, Im E-O, Tyler DO. Maternal Health Needs and Interest in Screening for Depression and Health Behaviors During Pediatric Visits. J Pediatr Heal Care. 2013;27(4):267-277. doi:10.1016/j.pedhc.2011.11.008.

62. Hewitt C, Gilbody S, Brealey S, et al. Methods to identify postnatal depression in primary care: an integrated evidence synthesis and value of information analysis. Health Technol Assess (Rockv). 2009;13(36):1-145, 147-230. doi:10.3310/hta13360.

63. Hearn G, Iliff A, Jones I, et al. Postnatal depression in the community. Br J Gen Pract. 1998;48(428):1064-1066.

64. Reid V, Meadows-Oliver M. Postpartum Depression in Adolescent Mothers: An Integrative Review of the Literature. J Pediatr Heal Care. 2007;21(5):289-298. doi:10.1016/j.pedhc.2006.05.010. 
65. Paulson JF, Bazemore SD. Prenatal and Postpartum Depression in Fathers and Its Association With Maternal Depression. JAMA. 2010;303(19):1961.

doi:10.1001/jama.2010.605.

66. Skari H, Skreden M, Malt UF, et al. Comparative levels of psychological distress, stress symptoms, depression and anxiety after childbirth--a prospective population-based study of mothers and fathers. BJOG. 2002;109(10):1154-1163. doi:10.1016/S14700328(02)00968-0.

67. Goodman JH. Paternal postpartum depression, its relationship to maternal postpartum depression, and implications for family health. J Adv Nurs. 2004;45(1):26-35. http://www.ncbi.nlm.nih.gov/pubmed/14675298. Accessed February 23, 2017.

68. Paulson JF, Dauber S, Leiferman JA. Individual and Combined Effects of Postpartum Depression in Mothers and Fathers on Parenting Behavior. Pediatrics. 2006;118(2).

69. RAMCHANDANI PG, STEIN A, O’CONNOR TG, HERON J, MURRAY L, EVANS J. Depression in Men in the Postnatal Period and Later Child Psychopathology: A Population Cohort Study. J Am Acad Child Adolesc Psychiatry. 2008;47(4):390-398. doi:10.1097/CHI.0b013e31816429c2.

70. Ramchandani P, Stein A, Evans J, O’Connor TG. Paternal depression in the postnatal period and child development: a prospective population study. Lancet. 2005;365(9478):2201-2205. doi:10.1016/S0140-6736(05)66778-5.

71. Kahn RS, Brandt D, Whitaker RC. Combined Effect of Mothers' and Fathers' Mental Health Symptoms on Children's Behavioral and Emotional Well-being. Arch Pediatr Adolesc Med. 2004;158(8):721. doi:10.1001/archpedi.158.8.721.

72. Chang JJ, Halpern CT, Kaufman JS. Maternal Depressive Symptoms, Father's Involvement, and the Trajectories of Child Problem Behaviors in a US National Sample. Arch Pediatr Adolesc Med. 2007;161(7):697. doi:10.1001/archpedi.161.7.697.

73. Mezulis AH, Hyde JS, Clark R. Father Involvement Moderates the Effect of Maternal Depression During a Child's Infancy on Child Behavior Problems in Kindergarten. J Fam Psychol. 2004;18(4):575-588. doi:10.1037/0893-3200.18.4.575.

74. Melrose S. Paternal postpartum depression: How can nurses begin to help? Contemp Nurse. 2010;34(2):199-210. doi:10.5172/conu.2010.34.2.199. 